\title{
FIOS DE UMA INFÂNCIA DE MATRIZ AFRICANA: O MENINO N NA OBRA DE ONDJAKI
}

\section{THREADS OF AN AFRICAN MATRIX CHILDHOOD: N THE BOY ON ONDJAKI'S WORK}

\author{
SANTOS, Izabel Cristina da Rosa Gomes dos \\ belgomes2712@gmail.com \\ NUVIC UFSC - Universidade Federal de Santa Catarina
}

\begin{abstract}
Resumo O texto propõe estabelecer uma relação conceitual ao articular infâncias e a literatura africana, aportes para se pensar os contextos na educação, sobretudo, por imagens literárias que compõem as infâncias na voz do escritor angolano, Ondjaki. Vale sinalizar que a ancoragem dessa discussão pauta-se na obra Os da minha rua, do referido escritor nascido sob o céu de Luanda. O texto aqui apresentado propõe, a partir de imagens literárias, encontrar-se com as infâncias narradas e escritas em terra africana para com isso, provocar e instigar nosso olhar sobre o modo pelo qual pensamos a infância. Entre outros fios, por outras linhas, o menino $\mathrm{N}$ nos apresenta as infâncias vividas e experimentadas e com isso, nos põe a tarefa de um profícuo diálogo entre literatura e uma infância de matriz africana.
\end{abstract}

Palavras-chave: Infância. Literatura Africana. Ondjaki.

Abstract The text proposes to establish a relationship a conceptual when articulate childhood and african literature, contributions to think education contexts, especially by literary images who compose the childhoods in the voice of the Angolan writer, Ondjaki. Is important to know that the anchoring of this discussion is guided in the book Os da minha rua, by the writer who has born under the sky of Luanda.The text here presented proposes, from literary images, to discover the childhoods narrated and written on african soil to, with it, tease and entice our eyes on the way we think the childhood. Among other wires, for other lines, $\mathrm{N}$ the boy, present to us the childhood he has lived and experienced, and with it, brings us the task of a deep dialogue between literature and a childhood of african matrix.

Keywords: Childhood. African literature. Ondjaki.

\section{INTRODUÇÃO}

Apenas vou reunindo vozes como brilhos num céu que às vezes me sucede demasiado escuro - estou certo que sabes ao que me refiro. Assim vou cruzando os dias, inventando o tempo, tecendo as vozes, reinventando as impossíveis constelações. (ONDJAKI, 2009, p. 184)

As palavras que seguem, reúnem as possíveis vozes literárias das crianças apresentadas acima e norteiam uma discussão acerca de literatura e educação, 
objetivando estabelecer uma relação conceitual ao articular infância e literatura africana, aportes para se pensar alguns contextos na educação, sobretudo, por imagens literárias que compõem as infâncias e o olhar de um escritor angolano. Importa-se refletir, sob a luz das infâncias narradas e escritas de terras angolanas, o que estas infâncias nos educam. Busca-se, portanto, refinar o modo pelo qual pensamos a infância, tendo como aporte a obra "Os da minha rua", do escritor angolano Ondjaki, que apresenta infâncias experienciadas e nos coloca a tarefa de um profícuo diálogo entre literatura e uma infância de matriz africana. O referido escritor $^{1}$, nascido sob o céu de Luanda, situa sua trajetória entre prosa e poesia e seu processo de escrita é atravessado por histórias escritas e contadas, por experiências de leituras e por uma notada sensibilidade voltada para a infância.

Vale ressaltar, suas palavras:

Ela (a infância) me arrebata por ser tão inesperada, surpreendente, instintiva, livre. Foge das lógicas dos adultos. Inventa caminhos, implica uma visão poética que a vida nos suga. $E$ as crianças têm acesso livre a essa lógica do momento, da imaginação, das não barreiras. Todo o olharde-criança é um poema pronto a explodir. E explode mesmo. (ONDJAKI, julho/2012)

O texto aqui apresentado propõe, a partir de imagens literárias da obra, encontrar-se com as infâncias narradas e escritas em terra angolana, para com isso provocar e instigar nosso olhar sobre o modo pelo qual pensamos a infância. $O$ encontro com Os da minha rua, com as crianças que transitam pelas cenas literárias, possibilita pensar: o que educa a infância? Em que sentido, o encontro com uma infância de matriz africana nos proporciona pensar a infância? E para tanto, interrogar-se sobre o que se apreende desses sujeitos-crianças, vozes por vezes silenciadas ou até mesmo sobrepostas em outras vozes.

\footnotetext{
${ }^{1}$ Sua trajetória é acompanhada por premiações literárias:

- 2007: Finalista do prêmio "Portugal TELECOM" (Brasil), com "Bom dia Camaradas".

- 2008: Finalista do prêmio "Portugal TELECOM" (Brasil), com "Os da minha rua".

- 2010: Prêmio Jabuti, categoria Juvenil, com "AvóDezanove e o Segredo do Soviético".

- 2012: Fundação Nacional do Livro Infantil e Juvenil brasileira, categoria melhor título destinado a crianças e jovens, com "A Bicicleta Que Tinha Bigodes"

- 2012: Prêmio Bissaya Barreto 2012, com "A bicicleta que tinha bigodes" (Portugal)

- 2013: Prêmio Saramago, com "Os Transparentes"
} 
Um dos princípios desse movimento é delinear um conceito de infância que possa transitar, dançar, deslocando-se de uma imagem de maior obviedade que temos construído sobre a infância para, então, habitar outras possíveis imagens, com contornos que dizem do lugar, dos cheiros, da terra, das lutas, da palavra. Desarraigar-se de um lugar confinado e compreender a infância na/pela palavra; pensar a infância como um conceito em deslocamento, em mobilidade e que possa habitar outras esferas possíveis, se traduz aqui, nosso desafio, portanto, "[...] não basta dizer: os conceitos se movem. É preciso ainda construir conceitos capazes de movimentos intelectuais". (DELEUZE, 1992, p. 152).

Deste modo, partir de/para outros lugares, para desarticular uma imagem imediata e transitar pela pluralidade da infância permite-nos compor linhas de relação, traços de experiência ${ }^{2}$ entre muitas outras infâncias.

\section{ALGUNS FIOS QUE TECEM OS DISPOSITIVOS LEGAIS}

Embora o foco deste texto seja a literatura africana e o que ela nos revela para pensar o conceito infância, importa registrar que os dispositivos legais brasileiros apontam para uma ampliação das discussões acerca do lugar ocupado pela cultura afro-brasileira, em especial, a firmação e reconhecimento da presença africana compondo a sociedade brasileira.

Importa lembrar que a Lei de Diretrizes e Bases da Educação Brasileira (LDB 9394/96), legislação que regulamenta o sistema educacional público ou privado do Brasil (da educação básica ao ensino superior), sustenta o aspecto organizativo dos currículos educacionais. Essa organização curricular teve alteração, a partir das lutas do movimento negro (entre as principais bandeiras está o Estatuto da Igualdade Racial). O diálogo com esses movimentos permitiram a expressão de uma transformação social, movimentos de luta, culminando com o sancionamento da lei 10.639/2003, na qual se incluiu no currículo oficial das redes de ensino a obrigatoriedade da temática História e Cultura Afro-Brasileira.

Retomo aqui o artigo 26:

\footnotetext{
${ }^{2}$ Entendendo a experiência como algo "que nos acontece, o que nos toca. Não o que se passa, não o que acontece, ou o que toca”. (LARROSA, 2004, p. 21). Grifos meus.
} 
$\S 1^{\circ} O$ conteúdo programático a que se refere o caput deste artigo incluirá o estudo da História da África e dos Africanos, a luta dos negros no Brasil, a cultura negra brasileira e o negro na formação da sociedade nacional, resgatando a contribuição do povo negro nas áreas social, econômica e política pertinentes à História do Brasil. (BRASIL, 2003, p. 07)

Embora essa lei proponha novas diretrizes para afirmar a relevância de se valorar as matrizes culturais que fizeram do Brasil o país múltiplo e plural que somos, ela (a lei) teve uma implementação somente a partir da lei 11.645/2008 e apresentou como protagonista a comunidade indígena. Portanto, nesse contexto, os protocolos jurídicos dizem que as leis 10.639/2003 e 11.645/2008 inserem no currículo nacional brasileiro a história, cultura, memória e pertencimentos das comunidades negras, africanas e indígenas.

Essas alterações fazem-se presente no artigo $1^{\circ}$ da lei $11.645 / 2008$, no qual o artigo 26-A da Lei no 9.394, de 20 de dezembro de 1996, passa a vigorar com a seguinte redação:

$\S 1^{\circ} \mathrm{O}$ conteúdo programático a que se refere este artigo incluirá diversos aspectos da história e da cultura que caracterizam a formação da população brasileira, a partir desses dois grupos étnicos, tais como o estudo da história da África e dos africanos, a luta dos negros e dos povos indígenas no Brasil, a cultura negra e indígena brasileira e o negro e o índio na formação da sociedade nacional, resgatando as suas contribuições nas áreas social, econômica e política, pertinentes à história do Brasil. $\S 2^{\underline{0}}$ Os conteúdos referentes à história e cultura afro-brasileira e dos povos indígenas brasileiros serão ministrados no âmbito de todo o currículo escolar, em especial nas áreas de educação artística e de literatura e história brasileiras. (BRASIL, 2008, p. 01).

As leis acima citadas referendam uma conquista histórica de ativistas e incansáveis lutas para a concretização de políticas afirmativas. A ancoragem nesses dispositivos e seus movimentos sugerem deslocar uma força que propicia encontros, reconhece as instituições educativas como lugar de formação de cidadãos e afirma a relevância de valorizar as matrizes culturais que fizeram do Brasil o país múltiplo e plural que somos.

Portanto, vale aqui enfatizar, as experiências do olhar, que assinalam para a compreensão de que "Enxergar a África, talvez seja, ver o mapamúndi [sic] pelo avesso, porque ela nos traz tantas forças, verdades, sons, cores, palavras e 
sotaques nos revelando as africanidades" (TORRES, 2009, p. 68), reafirmando, assim, raízes multiculturais refletidas em culturas que consideram o ouvir, a sonoridade das palavras e a memória.

Partindo dos dispositivos legais, em busca de entrelaçar literatura e cultura africana, convido para um pensar acerca das infâncias.

\section{INFÂNCIAS: UM EXERCÍCIO DE INQUIETUDES}

Discorrer acerca das infâncias em diálogo com Literaturas Africanas exige, primeiramente, um exercício de traços e esboços. Anuncio que, embora as áreas do conhecimento (antropologia, psicologia, história, sociologia e filosofia) cooperem para pensar a infância, traço uma escolha metodológica a partir das contribuições das áreas da sociologia e filosofia (SARMENTO, 2004 e 2009; LEITE, 2011; DORNELLES, 2011; KOHAN, 2009; DELEUZE e GUATTARI, 1992.) e as possiveis linhas com as Literaturas Africanas. Considerar essas áreas do conhecimento e suas contribuições para a educação é compor um olhar apurado para os "[...] trabalhos de pesquisa que procuram resgatar a infância como objeto de conhecimento, nas suas múltiplas articulações com as diversas esferas, categorias e estruturas da sociedade." (SARMENTO; GOUVÊA, 2009, p. 09).

No contexto social há distintas percepções da infância, constituindo nossos discursos a partir de uma forma de pensar a infância, ou seja, "os modos de conceber a infância estão diretamente relacionados aos modos de lidar com a criança e esses por sua vez acabam indicando formas de pensar e refletir a infância." (LEITE, 2011, p. 28). Há de se considerar que esses discursos, de certa maneira, estão relacionados a uma prática educativa, ou seja, refletem não somente teorias, mas também indicam atravessamentos sociais e históricos acerca da infância.

Portanto, como se olha a criança através dos contextos familiares, na unidade educativa, nas relações sociais, coabitam uma forma de infância generalizada e que, por vezes, Ihe subtraem o seu lugar de direito. Os efeitos desses discursos predominantes anunciam como as pessoas pensam as crianças e a infância, ou seja, configuram um viés único, imediatista, como se a infância não fosse plural. 
Atento para a presença de uma diversidade na infância, pois sendo sujeitos sociais estão inseridos em diferentes arranjos sociais (camada social, gênero, raça), o que exige a busca "[...] do lugar que a contemporaneidade reservou para a criança e, sobretudo, do lugar que a criança, todas as crianças, contrói(oem) na sua interação mútua, na edificação dos seus mundos de vida e das suas culturas." (SARMENTO, 2004, p. 10).

Nessa trajetória, importa perceber que a infância teve/tem seu traço marcado por um modelo universal de criança e regido pelo poder adulto. Entendo a necessidade de transpor essa visão para se alcançar um olhar atento aos diferentes tempos históricos e configurações sociais em que a criança vive e ao que ela nos revela. Ressalvo a importância do conceito de emergência da infância, que "[...] vai se produzindo no interstício destes séculos, em cada momento histórico, fixando-se em cada ritual, impondo obrigações e direitos, estabelecendo marcas nas coisas e nos corpos." (DORNELLES, 2011, p. 19). A esse conceito, soma-se a contribuição das áreas do conhecimento, já anunciadas, para constituir um olhar ampliado, o dentro e fora de um mesmo território, inter-relações, inter-tempos, inter-contextos, construção de pesquisas. Penso que esses traços anunciam a polissemia desses discursos e a partir deles, indicam o que se pode (re)pensar de nossas práticas, nosso trânsito nesse lugar de potencialidades, as quais por vezes nos impõe incertezas e nos coloca em movimento.

Nessa direção, sigo a traçar um caminho que permita pensar a infância, entrelaçá-la com a literatura, em uma escrita-encontro, em queda livre ao rompimento da linearidade do tempo, ao entendimento de que "[...] a infância tem a ver com revisitar certos lugares como se fosse a primeira visita." (KOHAN, 2009, p. 40) Interrogo o quanto essa 'primeira visita', demanda desprendimentos do que sabemos e ciência de que nosso saber está ajustado em uma lógica adulta e irredutível. Acredito que as vozes das crianças nos lugares onde estão (onde, de verdade, estão), fazem-nos pensar a infância em um exercício que exige inquietudes, ruptura de paradigmas e um se dar a ouvir as crianças.

\section{4 'OS DA MINHA RUA': UMA INFÂNCIA EXPERENCIADA}


Viagem de uma experiência de pensamento que inquieta e impede de continuar a pensar da maneira que se pensava. Viagem de polêmica e desacordos. Experiência de interrogação e de fratura da própria experiência. (KOHAN, 2004, p. 54)

A escolha para este texto, partindo de uma viagem e experiência do pensar, evidencia um contexto infantil constituído por lampejos de uma possível realidade captada pelo escritor angolano, que ao escrever reelabora suas relações com o vivido e com as infâncias, mesmo partindo do lugar de adulto. Assim, iniciemos a investigação da obra Os da minha rua, a qual mesmo não apresentando um desenvolvimento temporal, nem tampouco uma sequência linear das narrativas, evidencia a presença de pontos de interferência entre elas.

Essa análise tem como anfitrião um menino-narrador, de agora em diante, Menino $\mathrm{N}^{3}$. É por ele que as narrativas serão apresentadas e assim sendo, considera-se aqui a ideia do personagem conceitual que é o porta-voz de uma filosofia, de um dizer, no sentido de que "Eu não sou mais eu, mas uma aptidão do pensamento para se ver e se desenvolver através de um plano que me atravessa em vários lugares". (DELEUZE; GUATTARI, 1992, p. 85-86 - grifos meus).

Logo, pelas mãos do Menino $\mathrm{N}$, emergem centelhas de experiências reveladoras de amizades, relações com o mundo, risos, lugares e saberes infantis (des)concertantes.

O Menino $\mathrm{N}$ conduz a essa viagem de experiência pela obra, sempre em primeira pessoa, com verbos no pretérito e sob o ritmo da oralidade ${ }^{4}$. Decompõe espaço/tempo em narrativas curtas, instala, nesse enredo, o cenário de uma infância possível em Luanda: a rua, a escola, os amigos, o arranjo familiar, professores, despedidas, amores, cores, cheiros e histórias.

Importa, aqui, buscar os enlaçamentos que o Menino $\mathrm{N}$ desvela entre o seu vivido e as suas invencionices. Almeja-se, à guisa de convite, seguir pelas sendas dessa memória construída e inventada pela palavra, na tentativa de

perceber que essa palavra eclode em múltiplos sentidos, nos põe como tarefa pensar nessa experiência que pode desdobrar-se num enigma seguido por infinitos deslizamentos conceituais. Pensar [...] e conhecer o

\footnotetext{
${ }^{3}$ Convite para possíveis leituras deste trabalho: apresento o pacto de leitura acerca do Menino N, que pode ser considerado Menino Narrador, ou Menino Ndalu. Isso é uma escolha de quem lê.

${ }^{4}$ Vale atentar a acuidade do autor em manter, sempre que possível, o léxico da língua portuguesa falada em Angola.
} 
que ainda não conhecemos, de saber o que ainda não sabemos. (CAMPOS; LIMA, 2012, p. 149-150 - grifos meus) $)^{5}$.

Deste modo, segue uma leitura que já no conto de abertura "O voo do Jika" (p. 17), acontece o primeiro chamamento ao leitor: saltar com o Menino $\mathrm{N}$ e com o amigo Jika de um telhado, relativamente baixo, usando um guarda-chuva como paraquedas.

Lá embaixo estava a relva verde do jardim. O Jika abriu um muito, muito pequenino guarda-chuva azul.

- Põe a mão aqui - ensinou-me - Agora podemos saltar.

- Tens a certeza? - olhei para baixo.

- Vamos só.

Saltamos.

A infância é uma coisa assim bonita: caímos juntos na relva, magoamo-nos um bocadinho, mas sobretudo rimos. (ONDAJKI, 2007, p.19).

Essa cena, desprendida das tantas acrofobias (físicas e emocionais) que os adultos cultivam, apresenta o tom da leitura que se segue: subverter a lógica do cotidiano e, especialmente, do riso, fazendo com que o leitor possa construir um pensar que ressoe o riso. Aponta essa cena para o riso que dialoga, "[...] com o sério, que dança com o sério; ou melhor, desse riso que faz dialogar o sério, que o tira de seus esconderijos, que o rompe, que o dissolve, que o coloca em movimento, que o faz dançar". (LARROSA, 2003, p. 169). E igualmente seguirá essa leitura, sob flashes do experienciado em Os da minha rua, buscando um habitar no riso e na infância.

No encontro peculiar das sensações e da franqueza, sucede a narrativa "A televisão mais bonita do mundo" (ONDAJKI, 2007, p. 21), em que o Menino N, levado pelo Tio Chico para a casa do amigo Lima, conhece uma televisão colorida. A experiência imagética impede-o de calar diante do que vê, e expressa no auge de uma sinceridade sem receios: "'Chéeeeeee, essa televisão é bem esculú', e todos riram do meu espanto assim sincero: era a primeira televisão a cores que eu via na minha vida". (ONDAJKI, 2007, p. 25) ${ }^{6}$. E, a partir de imagens coloridas nessa

\footnotetext{
${ }^{5}$ Texto original do francês apresentado por minha livre tradução.

6 Esculú: muito bom, corruptela de "exclusivo". (ONDAJKI, 2007, p. 158)
} 
televisão, bonita como uma aquarela, ele encanta-se com o que vê e fica a pensar se os primos acreditariam nas cores exageradas da televisão do Lima.

O episódio envolve um encantamento que o permite expressar seu sentimento sem receio da reação dos adultos, essa sinceridade sem receios também aparece na opinião do Menino $\mathrm{N}$ sobre as mobílias que o Lima vendia: "Eu não gostava dos móveis que o Lima vendia, mas aquelas cadeiras até que eram fixes ${ }^{7}$, pintadas de uma cor clara com fitas assim de um plástico verde" (ONDAJKI, 2007, p. 23 - grifos meus).

Esse modo de inventariar o mundo, de encontrar soluções e dizer o que vê e sente sem medo, multiplica-se na certeza de "que a importância de uma coisa há que ser medida pelo encantamento que a coisa produza em nós". (BARROS, 2006, s.p).

Embora, o Menino $\mathrm{N}$ traceje um cotidiano sensorial repleto de cores, cheiros e bonitezas $^{8}$, inundado por uma linguagem lírica, ele também é tomado por algumas dores, perdas e despedidas.

O relato de perda em "O portão da casa da tia Rosa" (ONDAJKI, 2007, p. 95) apresenta-se cingido pelo choro do Menino N: "se me sacudissem podiam cair mais lágrimas" (ONDAJKI, 2007, p. 98). Nesse conto, com o desaparecimento da tia Rosa e do tio Chico, a angústia toma conta do menino, especialmente pelo silêncio que invadiu a casa: "Mas não me apetecia estar ali sem a tia Rosa e sem o tio Chico. Olhei o pequeno lago quase na saída, e também não vi os cágados. Nem vozes, nem barulhos de vizinhança. Nada". (ONDAJKI, 2007, p. 98).

Essas imagens intensificam-se no enredo, especialmente no choro contido (e por que não sentido?), na interferência do adulto (professora) dentro do espaço da instituição educativa e nas manifestações infantis de escrita e leitura. Em um desses quadros narrativos, "Os calções verdes do Bruno" (ONDAJKI, 2007, p. 101), o Menino $\mathrm{N}$ revela o gesto velado de uma carta amorosa do colega Bruno para Romina: "[...] Ainda por cima de noite só sonho com os caracóis de teus cabelos tipo cacho de uva..." (ONDAJKI, 2007, p. 102).

\footnotetext{
${ }^{7}$ Excelente, perfeito, bom.

${ }^{8}$ Empréstimo lexical de Guimarães Rosa.
} 
A cena acontece na instituição Mutuyakevela e tem uma intervenção abrupta do adulto, mesmo sendo uma pura manifestação da escrita, mesmo sendo "[...] uma das cartas de amor mais bonitas que ia ler na minha vida, e eu próprio, anos mais tarde, ia escrever uma carta de amor também muito bonita, mas nunca tão sincera como aquela" (ONDAJKI, 2007, p. 103). A situação finda com a carta rasgada pela professora em pedaços pequeninos, assim como as lágrimas de Bruno e do Menino $\mathrm{N}$, ou seja, evidencia-se o silenciamento preso a concepções adultocêntricas. Pontua-se, aqui, que essas concepções, são "[...] práticas centradas nos interesses dos adultos, mas destinadas à criança e ao adolescente, sem ouvi-los; exteriores aos desejos do outro, aos seus saberes" (SOUSA, 2010, p. 25).

Outro quadro de silenciamento também se observa no conto "Bilhete com foguetão" (ONDAJKI, 2007, p. 85), quando o Menino N expõe sobre sua experiência com o bilhetinho para Petra, menina bela e dona de uma mochila colorida que the chamava a atenção. O Menino N, só com olhos para Petra, passa o intervalo da aula tentando escrever um bilhete com desenho de um foguete para dizer que ela tinha "[...] um estojo bonito com cores de Carnaval da Vitória e a mochila também, pele tipo mousse de chocolate e uns olhos que, de longe, pareciam duas borboletas quietas e brilhantes [...]" (ONDAJKI, 2007, p. 87). No entanto, Marisa, sua colega de carteira entrega o bilhete para a delegada ${ }^{9}$ da turma, que lê, debocha do menino num gesto de autoritarismo e sob o silêncio do constrangimento ele abafa as lágrimas e a humilhação: "[...] cruzei os braços na carteira, escondi a cabeça, fechei os olhos, e pelos risos eu ia entendendo o que se passava ali" (ONDAJKI, 2007, p. 87).

Nesses dois eventos narrativos, vale ressaltar que se a infância tece o domínio da imaginação e da reinvenção das coisas, seria, talvez, o momento de refletir a postura dos adultos que convivem com as crianças, especialmente em que medida a intervenção e o discurso não são pautados em uma convenção adultocrática, ou seja, tomados pelo "discurso que faz valer a palavra e as concepções do adulto; que submete o outro, nesse caso a criança e o adolescente, aos olhares e às práticas considerados pelos adultos adequados para eles" (SOUSA, 2010, p. 27).

\footnotetext{
${ }^{9}$ Uma espécie de monitora ou líder de turma.
} 
No que se refere às práticas cotidianas em contextos de educação, o quanto, em nome da ordem, não se atropela as condições aiônicas ${ }^{10}$ vividas pelos sujeitoscriança que transitam nesses espaços-tempos de infância? Ou seja, o quanto há de se refletir acerca de dois tempos: o tempo khrónos (sequencial, sucessivo) e tempo aión (temporalidade não numerável, não sucessiva, intensa e qualitativa). Talvez, a partir desse menino-narrador, seja possível perceber que a infância oferece uma temporalidade aiônica, ou seja, descontínua, durativa e intensiva, que "[...] habita a temporalidade do acontecimento, da experiência, da interrupção da linearidade histórica em busca de um novo começo" (KOHAN, 2010, p. 132).

E, o desenrolar da narrativa aciona modos de existência, interrompendo tempos padronizados pelas convenções adultocêntricas, nos quais não há, na maioria das vezes, espaços para outros olhares possíveis. A experiência de leitura dessas narrativas de Ondjaki abre-nos ao diálogo entre textos, ao compromisso de converger pensamentos e aproximarmo-nos do que ainda não conhecemos; é o que nos provoca e podemos pensar, escrever e sentir a partir das palavras escritas/lidas. É considerar que a imaginação infantil "trabalha subvertendo a ordem estabelecida, pois, impulsionada pelo desejo e pela paixão, ela está sempre pronta para mostrar uma outra possibilidade de apreensão das coisas, do mundo e da vida. (JOBIM e SOUZA, 1994, p. 149).

Outra experiência do Menino $\mathrm{N}$ com o envolvimento da leitura aparece em "Nós choramos pelo Cão Tinhoso" (ONDAJKI, 2007, p.131) em que ele é convocado a ler o denso conto Nós matamos o Cão Tinhoso, do escritor moçambicano Luis Bernardo Honwana ${ }^{11}$. A relação da leitura é de entrega e emoção, tanto pelo que diz o texto, como pelo movimento da leitura profunda que envolve aquela sala de aula. O Menino N, já conhecia o conto, "sabia que aquele texto era duro de ler. Mas nunca pensei que umas lágrimas pudessem ficar tão pesadas dentro de uma pessoa" ( $p$. 99).

\footnotetext{
${ }^{10}$ Kohan, 2010.

${ }^{11}$ Escritor nascido em 1942 sob as estrelas de Moçambique. Teve formação jornalística e apoiou a luta pela libertação do país e esteve preso em 1964, por três anos. O texto Nós Matamos o CãoTinhoso publicado (1969) em língua inglesa, obteve divulgação e reconhecimento internacional. Após a independência de Moçambique, Luis Bernardo Honwana desempenhou diversos cargos políticos chegando a ser Ministro da Cultura. Informações retiradas de: http://www. pluraleditores.co.mz/PLE04.asp?area=3\&ID=05
} 
Por conseguinte, sentia a tensão crescente das feridas penduradas do cão, da Isaura que amava o Tinhoso e dos tiros mortíferos do fim do conto. Mesmo conhecendo o enredo, quase não segura as lágrimas e arrasta-se de tal forma nesse fluxo de leitura estabelecendo a ideia de que ler é "recolher o que se vem dizendo para que se continue dizendo outra vez [...] como sempre se disse e como nunca se disse, numa repetição que é diferença e numa diferença que é repetição" (LARROSA, 2003, p.141).

A relação com o tempo é, também, evidenciada em "O último Carnaval da Vitória" (ONDAJKI, 2007, p. 59,) abordado sob a perspectiva do tempo aión (KOHAN, 2010) o qual tem como profundeza ser durativo e intenso: "vivíamos num tempo fora do tempo [...] Para nós segunda-feira era um dia de começar a semana de aulas e sexta-feira significava que íamos ter dois dias sem aula" (p. 59). O modo de 'medir' o tempo, fora dos ponteiros do relógio, bem ao sabor infantil, também é apontado em: "lembro-me disso porque nós sabíamos as horas pelo modo como as sombras invadiam a sala de aula" (ONDAJKI, 2007, p. 65).

Essa percepção do tempo intenso aparece, ainda, no momento das gargalhadas embaladas em vinte minutos de recreio:

Uns traziam lanche, outros não; uns tinham bola e carrinhos bonitos, outros não; todos vínhamos vestidos com fardamento azul, de modo que no intervalo a escola ganhava uma gritaria toda azul de crianças a quererem aproveitar aqueles vinte minutos de liberdade e maluqueira. [...] No dia seguinte corríamos outra vez. (ONDAJKI, 2007, p.121 - grifos meus).

E fica para refletir o significado do recreio nas instituições coletivas de educação, o curto espaço de tempo recheado por correria e "gritaria azul". O que seria revelado nesses momentos e o quanto os adultos participam efetivamente desses momentos de parque (ou pátio), ou seria somente um momento de catarse das crianças diante do vivido nas salas de aula? Quais seriam os significados atribuídos ao recreio, sejam brincadeiras, o lanche, a liberdade de correr ou até mesmo as brigas? E aqui, acredito, que não há um significado ou uma única interpretação para o período do recreio. São pluralidades que anunciam múltiplas influências e alteram-se conforme as experiências vivenciadas e que pouco conhecemos, 
Talvez porque esse lugar (o recreio ou o parque) reserve algumas surpresas, descobertas, mistérios - há sempre um bicho escondido em algum buraquinho, um pássaro que voa baixo, uma árvore na qual possam subir, um buraco para ser explorado, amigos e irmãos para encontrar, possibilidade de construir e desconstruir enredos, histórias e fantasias entre tantas outras coisas que só um olhar sensível e atento e uma escuta apurada é capaz de capturar. (BATISTA, 2008, p. 64)

Os diferentes elementos que compõem o momento do recreio interferem nos significados que ele pode ter, tanto para as crianças quanto para os adultos que partilham esses momentos. Assim, uma gritaria azul pode revelar diferentes sentidos e tempos. É nesse ponto que o Menino $\mathrm{N}$ traduz pela perspectiva aiônica um dos saberes infantis mais complexos ao olhar adulto: "[...] o tempo para a criança é puro instante, o instante infinito da intensidade, da ocasião, da oportunidade, é o tempo constituído pela simultaneidade, pela experiência da des-memória e da invenção" (CAMPOS; LIMA, 2012, p. 151) ${ }^{12}$.

Deste modo, com a vida em pleno movimento, o menino rege um desbravar de sensações e sentimentos a partir de uma experiência que nos acontece (LARROSA, 2004). E, portanto, estabelece com o leitor um tecer de possibilidades, de afetar-se, de perceber as histórias e os segredos lentos do tempo: "O vento voava devagar, as folhas da figueira faziam um ruído que era mais um segredo que um barulho" (ONDAJKI, 2007, p. 64).

Os da minha rua percorre uma crescente dimensão de sentidos, de tal modo, que o Menino $\mathrm{N}$ desenvolve com o leitor uma relação sinestésica de despedida, saudade e lágrimas abafadas. Uma dessas manifestações pode ser sentida no conto "Um pingo de chuva" (ONDAJKI, 2007, p. 119). A cena, no apartamento dos professores cubanos, ocorre em uma "[...] tarde quase bonita numa cor amarela e castanha que o Sol tinha dentro do apartamento pequeno deles" (ONDAJKI, 2007, p. 121). Nessa despedida, aflora o modo de reinventar das crianças, o modo de arrumar no coração lágrimas e saudades. $O$ quadro finaliza com a afinidade entre despedida com cheiro de amizade cinzenta, o por do sol e o sentimento das crianças: "Quando chegamos lá em baixo, o Sol já tinha ido embora. O céu queria começar a ficar escuro e, muito atrás de todas as nuvens que podíamos ver, um resto de encarnado vivo iniciou a despedida dele" (ONDAJKI, 2007, p. 123).

\footnotetext{
${ }^{12}$ Texto original do francês apresentado por minha livre tradução.
} 
Essa atmosfera de despedia, sob um efeito descritivo de sensibilidades, também aparece no último conto do livro, "Palavras para o velho abacateiro" (ONDAJKI, 2007, p. 137), em que sucede a transição do Menino $\mathrm{N}$, entre infância e a idade adulta (saída da casa dos pais). A cena desencadeia-se sob uma tempestade que encharca o corpo e a alma do menino: "[...] parei um pouco a deixar a chuva cair sobre a cabeça, fechando os olhos, escutando o ruído que ela fazia cá fora no mundo e dentro de mim também, queria ver quantos pensamentos eu podia inventar - e pensar [...]". (ONDAJKI, 2007, p. 138).

$E$, diante da perspectiva de viajar, de deixar 'sua rua', o menino entrega-se aos barulhos e cheiros que não poderia dividir com ninguém, porque essa partida "[...] de repente me chegava fora do tempo, num terreno que ia muito além da dor e das lágrimas, num lugar que nenhum escrito meu podia ter conseguido explicar nem nenhuma lágrima conseguiria apagar [...]”. (ONDAJKI, 2007, p. 143-144)

Então, em meio a uma profusão de imagens, transita pelo quarto, pela casa, pelas vivências, pelo tempo/espaço das memórias, pelos silêncios e as fissuras do passado. No quarto, a porta aberta mostra um rasgo de luz que o chama para mais uma experiência sensorial, anunciando mudanças:

[...] entendi que havia uma nesga aberta nos vidros e, por ali, todas as vozes da tarde, da chuva, da trepadeira, das árvores, entravam pelo meu quarto para me dar sinais estranhos que o meu corpo não sabia aceitar, nem a minha cabeça, uma vontade de lágrimas me visitou, cocei a pele da bochecha que era um gesto antigo para falar com as minhas vozes de dentro [...]. (ONDAJKI, 2007, p. 141-142 - grifos meus)

$\mathrm{O}$ conto celebra um rito entre a infância e a decisão de partir e o Menino $\mathrm{N}$ transforma-se em $\mathrm{N}$, deixa de ser só um menino e leva no baú das memórias suas vivências, experiências de formação: a instituição educativa, a casa, a rua, lesmas no quintal, amigos, cheiros e cores. A árvore, companhia de tantas cenas, velha amiga de tantos segredos, testemunha essa passagem, e $\mathrm{N}$ não reconhece mais as 'palavras' do abacateiro: "[...] não soube mais entender e pode ter sido nesse momento que no corpo de criança um adulto começou a querer aparecer, não sei, há coisas que é preciso perguntar aos galhos de um abacateiro velho [...]" (ONDAJKI, 2007, p. 137). 
E ao sabor do tempo aión e da tempestade, $\mathrm{N}$ encerra um ciclo de imagens e memórias evocadas na linguagem apresentadas ao leitor. Resiste em assegurar o lugar infância, embora que nesse dia ela tenha ficado, "espremida numa só palavra que quase me doía na boca se eu falasse com palavras de dizer: infância" (ONDAJKI, 2007, p. 145).

\section{SABERES E SABORES: A CONVERSA CHEGA AO FIM}

Nesse sentido, sob o plano de múltiplas infâncias, seria possível apreender que o Menino $\mathrm{N}$ estaria subvertendo os lugares marcados pela lógica adulta e de certa forma, revelando possibilidades de leituras de um cotidiano inventivo? Recados do que a infância diz e vê do mundo? Mergulhar nessa inquietação pode vislumbrar outro traço da infância que permita "escrever outras escritas, inscrever outras leituras, outras infâncias, infâncias de outros, infâncias outras" (LEITE, 2011, p. 24) e ainda outros currículos?

Assim, a obra leva a refletir acerca das singulares e múltiplas experiências que configuram os contextos infantis, o quanto nos é preciso apreender suas práticas sociais e, especialmente, o quanto "essa cartografia oferece a leitura reveladora capaz de descortinar a força e a resistência do afeto, e entre trajetos e territórios, [...]. (CAMPOS; LIMA, 2012, p. 149-150)13. Quem sabe esse caminhar, possa ampliar as discussões que envolvem infâncias e literatura; e traga-nos como ponto de ancoragem uma inversão do olhar, pois

[...] pensar a infância desde outra marca, ou, melhor, a partir do que ela tem e não do que Ihe falta: como presença e não como ausência; como afirmação e não como negação; como força e não como incapacidade. Essa mudança de percepção vai (pode) gerar outras mudanças nos espaços outorgados à infância no pensamento e nas instituições pensadas para acolhê-la. (KOHAN, 2009, p. 41)

Compreendo, então, que infância é um brincar com a seriedade e sisudez do adulto, é um mudar os significados de lugar e reinventar sentidos, ou seja, reinventam os dias, refazem enredos, indicam outro transitar pelas sendas do mundo. Logo, essas relações são constituídas a partir de distintas experiências e situações de aprendizagem, já que a criança, diariamente, expressa e confirma sua

\footnotetext{
${ }^{13}$ Texto original do francês apresentado por minha livre tradução
} 
mobilidade no mundo, o quanto dizem, o quanto surpreendem e como tratam o tempo. E o quanto ainda aprendemos.

\section{IZABEL CRISTINA DA ROSA GOMES DOS SANTOS}

Mestre em Literatura Africana. Atua na formação continuada da Rede Municipal de Ensino de São José/SC. Integrante do Núcleo Vida e Cuidado: estudos e pesquisas sobre violências (NUVIC/UFSC).

\section{REFERÊNCIAS}

BARROS, M. de. Memórias inventadas: a segunda infância. São Paulo: Planeta, 2006.

BATISTA, R. Cotidiano da Educação Infantil: Espaço Acolhedor de Emancipação das Crianças. Revista Zero-a-seis. Florianópolis. v. 10, n. 18, p. 53-67,julho $2008 .$. Disponível em: https://periodicos.ufsc.br/index.php/zeroseis/article/download/.../8077. Acesso: 23 out. 2014.

BRASIL. Lei n. 10.639 de 9 de janeiro de 2003. Altera a Lei 9.394, de 20 de dezembro de 1996, que estabelece as diretrizes e bases da educação nacional, para incluir no currículo oficial da Rede de Ensino a obrigatoriedade da temática "História e Cultura Afro-Brasileira", e dá outras providências. Disponível em: <http://www.planalto.gov.br/ccivil_03/leis/2003/L10.639.htm. Acesso em: 28 ago. 2014.

BRASIL. Lei $n^{\circ}$. 11.645/2008. Inclusão no currículo oficial da rede de ensino a obrigatoriedade da temática "História e Cultura Afro-Brasileira e Indígena". Disponível em: http://www.planalto.gov.br. Acesso em: 13 jul. 2014.

BRASIL. Lei $n^{\circ}$. 9.394/96, de 20 de dezembro de 1996. Lei de diretrizes e bases da educação. Estabelece as diretrizes e bases da educação nacional. Diário Oficial da União: Brasília-DF, 23 dez. 1996. Disponível em:

http://www.planalto.gov.br/ccivil_03/leis//9394.htm. Acesso em: 30 ago. 2014.

CAMPOS, D. F. de; LIMA P. de M. Souslesailes d'Éroset de Kairos: cartographiedesdérives et duhasarddanslesrécits de Lispector, Sarraute, Gide, Genet et Pompeia. In: POLLOCK, Jonathan (Sous la direction). PRATIQUES DU HASARD - Pour un matérialisme de la reencontre.Collection Études: Presses Universitaires de Perp ignan, 2012.

DELEUZE, G.; GUATTARI, F.; PRADO JR., B. O que é filosofia? Rio de Janeiro: Ed. 34, 1992.

DORNELLES, L. V. Infâncias que nos escapam: da criança na rua à criança cyber. Petrópolis: Vozes, 2011. 
HONWANA, L. B. Nós matamos o cão-tinhoso. São Paulo: Ática, 1980.

JOBIM e SOUZA, S. Infância e linguagem: Bakhtin, Vygotsky e Benjamin. Campinas: Papirus, 1994.

KOHAN, W. O. (org) Lugares da infância: filosofia. Rio de Janeiro: DP\&A, 2004.

KOHAN, W. O. Infância e filosofia. In: SARMENTO, M. J.; GOUVEAA, M. C. S. de. Estudos da infância: educação e práticas sociais. 2. ed. Petrópolis: Vozes, 2009.

KOHAN, W. O. Vida e morte da infância, entre o humano e o inumano. In: Educação e Realidade. Porto Alegre, v. 35, n. 3, p. 125-138, set./dez., 2010. Disponível em: http://seer.ufrgs.br/educacaoerealidade/article/view/13083. Acesso: 29 mai. 2014.

LARROSA, J. A operação ensaio: sobre o ensaiar e o ensaiar-se no pensamento, na escrita e na vida. Porto Alegre. 2004, v 29. Disponível em:

http://seer.ufrgs.br/educacaoerealidade/article/view/25417. Acesso em 25 mar. 2013.

LARROSA, J. Notas sobre a experiência e o saber de experiência. Revista Brasileira de Educação. 2002. Disponível em: http://educa.fcc.org.br/pdf/rbedu/n19/n19a03.pdf. Acesso em 23 mai. 2013.

LARROSA, J. Pedagogia profana - danças piruetas e mascaradas. Belo Horizonte: Autêntica, 2003.

LEITE, C. D. P. Infância, experiência e tempo. São Paulo: Cultura Acadêmica, 2011.

ONDJAKI. Os da minha rua. Rio de Janeiro: Língua Geral, 2007.

ONDJAKI. AvóDezanove e o segredo do soviético. São Paulo: Cia das Letras, 2009.

ONDJAKI. Todo o olhar-de-criança é um poema pronto a explodir. Agencia RF. http://agenciariff.com.br/site/NoticiaEntrevista/ShowEntrevista/81. Acesso em: 29/mai/2014. Entrevista concedida a Márcio Vassallo - julho/2012

SARMENTO, M. J. As culturas da infância nas encruzilhadas da $2^{a}$ modernidade. In: SARMENTO, M. J.; CERISARA, A. B. (org). Crianças e miúdos: Perspectivas sociopedagógicas sobre infância e educação. Porto: Asa, 2004, p.09-34.

SARMENTO, I J.; GOUVÊA, M. C. S. de. Estudos da infância: educação e práticas sociais. 2. ed. Petrópolis: Vozes, 2009.

SOUSA, A. M. B. de; MIGUEL, D. S.; LIMA, P. de M. Módulo 1: gestão do cuidado e educação biocêntrica. Florianópolis: UFSC-CED-Nuvic, 2010.

TORRES, F. L. Vozes e visões, cantos (griots) e cabelos: - AfriBrasil. In: LIMA, T. (Org). Griots - culturas africanas: linguagem, memória, imaginário. Natal: Lucgraf, 2009. 